\title{
Withdrawal from Chronic Nicotine Administration Impairs Contextual Fear Conditioning in C57BL/6 Mice
}

\author{
Jennifer A. Davis, ${ }^{1}$ John R. James, ${ }^{2}$ Steven J. Siegel, ${ }^{3}$ and Thomas J. Gould ${ }^{1}$ \\ ${ }^{1}$ Department of Psychology, Neuroscience Program, Temple University, Philadelphia, Pennsylvania 19122, ${ }^{2}$ Department of Pharmaceutics, Virginia \\ Commonwealth University, Richmond, Virginia 23298, and ${ }^{3}$ Department of Psychiatry, University of Pennsylvania, Philadelphia, Pennsylvania 19104
}

The effects of acute nicotine administration $(0.09 \mathrm{mg} / \mathrm{kg}$ nicotine), chronic nicotine administration $(6.3 \mathrm{mg} / \mathrm{kg} / \mathrm{d}$ nicotine for $14 \mathrm{~d})$, and withdrawal from chronic nicotine administration on fear conditioning in C57BL/6 mice were examined. Mice were trained using two coterminating conditioned stimulus ( $30 \mathrm{~s} ; 85 \mathrm{~dB}$ white noise)- unconditioned stimulus $(2 \mathrm{~s} ; 0.57 \mathrm{~mA}$ foot shock) pairings and tested $24 \mathrm{~h}$ later for contextual and cued fear conditioning. Acute nicotine administration enhanced contextual fear conditioning, chronic nicotine administration had no effect on contextual fear conditioning, and withdrawal from chronic nicotine administration impaired contextual fear conditioning. Plasma nicotine concentrations were similar after acute and chronic treatment and were within the range reported for smokers. During withdrawal, concentrations of nicotine were undetectable. An acute dose of nicotine $(0.09 \mathrm{mg} / \mathrm{kg})$ during withdrawal from chronic nicotine treatment reversed withdrawal-associated deficits in contextual fear conditioning. The results suggest that tolerance to the effects of nicotine on contextual fear conditioning develops with chronic nicotine treatment at a physiologically relevant dose, and withdrawal from this chronic nicotine treatment is associated with impairments in contextual fear conditioning. These findings provide a model of how the effects of nicotine on learning may contribute to the development and maintenance of nicotine addiction.

Key words: nicotine withdrawal; acetylcholine; hippocampus; addiction; learning; tolerance

\section{Introduction}

Despite known health risks associated with nicotine use, 46 million adults in the United States are smokers (Center for Disease Control, 2004). This demographic may reflect the low success rates associated with smoking cessation, which can be attributed to aversive somatic, affective, and cognitive symptoms associated with nicotine withdrawal (Snyder et al., 1989; Kenny and Markou, 2001). Understanding the behavioral and neurobiological changes that occur as acute nicotine use transitions to chronic use and that occur during withdrawal from chronic nicotine will aid in developing treatments for nicotine addiction.

Studies of the neural mechanisms of nicotine addiction have focused primarily on the reward pathways activated by nicotine (for review, see Fagen et al., 2003). However, the neural systems and cellular changes associated with hippocampus-dependent learning and memory are also involved in addiction (Hyman and Malenka, 2001; Nestler, 2002). Nicotine can enhance learning and memory (for review, see Levin, 2002; Tinsley et al., 2004), and drug-stimuli associations formed during acute nicotine use may contribute to cravings for nicotine (Lazev et al., 1999; Cag-

Received May 4, 2005; revised Aug. 10, 2005; accepted Aug. 14, 2005.

This work was supported by National Institute on Drug Abuse (NIDA) Grant DA017949 (T.J.G.), the Pennsylvania Department of Health (T.J.G.), Temple University (T.J.G.), and National Cancer Institute/National Institute on Drug Abuse Transdisciplinary Tobacco Use Research Center Grant P5084718 (the principal investigator was Dr. Caryn Lerman). J.A.D. was supported by National Institutes of Health-NIDA Training Grant T32DA07237. We give special thanks to Drs. Jeanne Wehner and Allan Collins for comments on a previous version of this manuscript.

Correspondence should be addressed to Dr. Thomas J. Gould, Department of Psychology, Temple University, Weiss Hall, Philadelphia, PA 19122. E-mail: tgould@temple.edu.

D01:10.1523/JNEUROSCI.2853-05.2005

Copyright $\odot 2005$ Society for Neuroscience $\quad$ 0270-6474/05/258708-06\$15.00/0 giula et al., 2001; Chiamulera, 2005). Furthermore, just as the acute effects of nicotine may contribute to nicotine addiction, the effects of withdrawal from chronic nicotine may also contribute to nicotine addiction. For example, nicotine withdrawal is associated with cognitive deficits in humans (Kleinman et al., 1973; Snyder et al., 1989). Thus, the initial enhancing effect of nicotine on learning and memory may reinforce repeated use, and chronic use may be maintained to avoid nicotine withdrawal-induced cognitive deficits.

Fear conditioning has been used to examine the effects of nicotine on hippocampus-dependent learning. In this task, subjects are trained in a context by pairing an auditory conditioned stimulus (CS) with a footshock unconditioned stimulus (US). Two associations are formed: an association between the training context and the US (contextual fear conditioning), which requires the hippocampus, and an association between the CS and the US (cued fear conditioning), which does not require the hippocampus (Phillips and LeDoux, 1992; Logue et al., 1997). An advantage of fear conditioning, which is particularly relevant to the present experiments, is that the task is rapidly acquired. Therefore, it is easy to examine the effects of acute drug administration, chronic drug administration, and withdrawal from chronic drug administration on the acquisition of this type of learning.

Acute nicotine enhances contextual fear conditioning (Gould and Wehner, 1999; Gould and Higgins, 2003; Gould et al., 2004; Wehner et al., 2004; Davis and Gould, 2005), but the effects of chronic and withdrawal from chronic nicotine on fear conditioning are unknown. In fact, no animal studies have examined the effects of chronic nicotine or withdrawal from chronic nicotine 
on the acquisition of a learning task. Therefore, the present studies examined the effects of chronic and withdrawal from chronic nicotine on contextual and cued fear conditioning to test whether treatment with a chronic dose of nicotine that produced plasma nicotine levels similar to those reported in smokers (Benowitz et al., 1989; Henningfield and Keenan, 1993) would produce tolerance and/or withdrawal-associated deficits.

\section{Materials and Methods}

Subjects. Male C57BL/6 mice (8-12 weeks of age; The Jackson Laboratory, Bar Harbor, ME) were housed in groups of four with ad libitum access to food and water. Separate mice were used for each experiment. All procedures occurred between 7:00 A.M. and 4:00 P.M. during the light phase of a $12 \mathrm{~h}$ light/dark cycle. Behavioral procedures and surgical procedures were approved by the Temple University Institutional Animal Care and Use Committee.

Surgery. Micro-osmotic pumps that administered $0.25 \mu \mathrm{l} / \mathrm{h}$ solution were filled with $100 \mu \mathrm{l}$ of nicotine solution $(6.3 \mathrm{mg} / \mathrm{kg} / \mathrm{d})$ or saline and inserted subcutaneously via an incision in the lower back of the mouse. Twelve days after the initial surgery, mice in the withdrawal treatment groups were subjected to a second surgery during which the microosmotic pumps were removed via a second incision in the lower back. Surgery was performed under sterile conditions with $5 \%$ isoflurane as the anesthetic.

Apparatus. Mice were trained in fear conditioning and tested for freezing to the context in conditioning chambers housed in soundattenuating boxes (MED Associates, St. Albans, VT). Each $17.78 \times$ $19.05 \times 38.10 \mathrm{~cm}$ chamber consisted of Plexiglas panels in the front, back, and ceiling and two stainless-steel walls on the sides. The metal grid floor of each chamber through which the foot shock US $(0.57 \mathrm{~mA})$ was delivered was connected to a shock generator and scrambler. Background noise and air exchange $(69 \mathrm{~dB})$ were provided by ventilation fans mounted on the right wall of each sound-attenuating box, and speakers that were used to deliver a white noise CS $(85 \mathrm{~dB})$ were mounted on the right wall of each chamber. An IBM (White Plains, NY) personal computer running MED-PC software was interfaced with the chambers and used to administer stimuli.

Testing for freezing to the CS occurred in a separate room in altered context chambers that were housed in sound-attenuating boxes. Speakers that delivered the white noise CS used at training were mounted on the left wall of each chamber. The $20.32 \times 22.86 \times 17.78 \mathrm{~cm}$ chambers were constructed of four Plexiglas walls, a Plexiglas ceiling, and a metal grid floor covered with opaque white plastic. In addition to the differences in location, visual cues associated with the location (e.g., the inside of the sound-attenuating boxes in the training context were white, and the inside of the sound-attenuating boxes in the altered context room were black), chamber dimensions, floor color, and construction, a vanilla extract olfactory cue (no olfactory cue was present in the training chambers) further distinguished the altered context chambers from the original training chambers.

Behavioral procedures. Mice were trained and tested in fear conditioning according to the study by Gould and Higgins (2003). Freezing was measured by observing mice for $1 \mathrm{~s}$ every $10 \mathrm{~s}$, and researchers were blind to the treatments. During the first $120 \mathrm{~s}$ of the $5.5 \mathrm{~min}$ training session, baseline freezing was assessed. Immediately following baseline freezing, the first of two CS ( $85 \mathrm{~dB}$ white noise)-US ( $0.57 \mathrm{~mA}$ foot shock) pairings occurred. The CS was presented for a total of $30 \mathrm{~s}$. Twenty-eight seconds after the CS onset, the $2 \mathrm{~s}$ footshock US was presented; the CS and US coterminated. The CS-US presentations were separated by a $120 \mathrm{~s}$ intertrial interval during which immediate freezing was assessed. After the second CS-US presentation, mice remained in the chamber for an additional $30 \mathrm{~s}$.

Twenty-four hours after training, mice were placed in the original training chamber. Freezing to the context was assessed over $5 \mathrm{~min}$. Cued fear conditioning was evaluated $1 \mathrm{~h}$ later in the altered context chambers. Freezing in the absence of the CS (preCS freezing) was assessed during the first $180 \mathrm{~s}$ of the test session. Next, the CS was presented for $180 \mathrm{~s}$, and freezing to the CS was assessed.
Drug administration and experimental groups. Nicotine hydrogen tartrate salt (Sigma, St. Louis, MO) was dissolved in saline and administered via intraperitoneal injection and/or micro-osmotic pump (model 1002; Alzet, Cupertino, CA). The first behavioral experiment compared the effects of acute, chronic, and withdrawal from chronic nicotine on fear conditioning. Mice treated acutely with saline $(n=14)$ or $0.09 \mathrm{mg} / \mathrm{kg}$ nicotine ( $n=14$; nicotine dose reported as freebase), a dose shown to produce long-lasting enhancement of contextual fear conditioning (Gould and Higgins, 2003), received injections $5 \mathrm{~min}$ before training and 5 min before testing (which occurred $24 \mathrm{~h}$ after training). To counterbalance for withdrawal procedures, sham pump implantations and removals were performed on 6 of the 14 mice treated with saline and on 6 of the 14 mice treated acutely with nicotine. Sham implantations occurred $12 \mathrm{~d}$ before training, and sham removals occurred $1 \mathrm{~d}$ before training. No differences were observed between mice in the acute condition that received sham treatments and mice that did not receive sham treatments. Thus, the data were combined for figure presentation and analysis.

Mice treated chronically with nicotine were prepared with pumps that administered $6.3 \mathrm{mg} / \mathrm{kg} / \mathrm{d}$ nicotine $(n=14$; nicotine dose reported as freebase) or saline $(n=14)$ for $14 \mathrm{~d}$. This dose of nicotine was chosen based on previous research indicating that chronic administration of doses as low as $6.0 \mathrm{mg} / \mathrm{kg} / \mathrm{d}$ produce significant increases in neuronal nicotinic acetylcholinergic receptor (nAChR) binding in C57BL/6 mice (Marks et al., 2004). In addition, this chronic dose of nicotine produced plasma nicotine levels in the chronically treated mice that were in the range reported for smokers (Benowitz et al., 1989; Henningfield and Keenan, 1993) and that were similar to those produced by an acute 0.09 $\mathrm{mg} / \mathrm{kg}$ dose of nicotine (see Results). Mice prepared with micro-osmotic pumps administering saline or nicotine were trained in fear conditioning $13 \mathrm{~d}$ after the pumps were implanted and tested $24 \mathrm{~h}$ later (day 14). To counterbalance for acute and withdrawal procedures, 6 of the 14 mice in each chronic treatment group received sham pump removal surgery $24 \mathrm{~h}$ before training (day 12) and saline injections 5 min before training on day 13 and $5 \mathrm{~min}$ before testing on day 14 . No differences were observed between sham-treated mice and mice that did not receive sham treatments. Thus, the data were combined for figure presentation and analysis.

Mice in the withdrawal condition were chronically treated with 6.3 $\mathrm{mg} / \mathrm{kg} / \mathrm{d}$ nicotine $(n=15)$ or saline $(n=15)$ for $12 \mathrm{~d}$ after which the micro-osmotic pumps were removed. Training occurred $24 \mathrm{~h}$ later on day 13 , and testing occurred on day 14 . To counterbalance for acute procedures, 6 of the 15 mice in each withdrawal treatment group received saline injections before training and testing. No differences were observed between mice that received saline injections before training and testing and mice that did not. Therefore, the data were combined for figure presentation and analysis.

A follow-up study was conducted to assess whether the effects of withdrawal from chronic nicotine on contextual fear conditioning (see Results) were attributable to administration of nicotine $1 \mathrm{~d}$ before training rather than to withdrawal from $12 \mathrm{~d}$ of chronic nicotine administration. Mice were trained $24 \mathrm{~h}$ after a single injection of either $0.09 \mathrm{mg} / \mathrm{kg}$ nicotine $(n=8)$ or saline $(n=8)$ and tested $1 \mathrm{~d}$ after training.

The final behavioral experiment examined whether acute nicotine $(0.09 \mathrm{mg} / \mathrm{kg} / \mathrm{d})$ administered during fear conditioning would reverse nicotine withdrawal-associated deficits in contextual fear conditioning. All mice were prepared with micro-osmotic pumps; half of the pumps delivered saline, and the remainder delivered $6.3 \mathrm{mg} / \mathrm{kg} / \mathrm{d}$ nicotine. Pumps were removed on day 12 of treatment. Mice were trained on day 13 and tested $24 \mathrm{~h}$ later. All mice received either acute saline or 0.09 $\mathrm{mg} / \mathrm{kg}$ nicotine injections before training and testing. Thus, four experimental conditions existed: (1) withdrawal from chronic saline with acute saline $(n=11)$, (2) withdrawal from chronic saline with acute nicotine $(n=11)$, (3) withdrawal from chronic nicotine with acute saline $(n=11)$, and (4) withdrawal from chronic nicotine with acute nicotine $(n=11)$.

Plasma nicotine and cotinine. Plasma samples were collected from the following four groups of untrained mice $(n=7-9)$ : (1) mice treated acutely with $0.09 \mathrm{mg} / \mathrm{kg}$ (intraperitoneally) of nicotine (samples collected $10 \mathrm{~min}$ after injection), (2) mice treated acutely with saline, (3) 
mice treated chronically with nicotine $(6.3 \mathrm{mg} / \mathrm{kg} / \mathrm{d}$ for $13 \mathrm{~d})$, and (4) mice withdrawn from chronic nicotine treatment $(6.3 \mathrm{mg} / \mathrm{kg} / \mathrm{d}$ for $12 \mathrm{~d}$ followed by $24 \mathrm{~h}$ of withdrawal). Mice were anesthetized with $5 \%$ isoflurane, and blood was obtained via cardiac puncture.

Nicotine/cotinine samples were analyzed using procedures adapted from Naidong et al. (2001). Briefly, a liquid chromatography (LC)/tandem mass spectrometry method validated for selectivity, calibration model fit, sensitivity, accuracy, and precision using a Micromass Quatro II LC mass spectrometer was used. Linearity for nicotine was $2.0-100$ $\mathrm{ng} / \mathrm{ml}$, and for cotinine was $1.0-600 \mathrm{ng} / \mathrm{ml}$. The inter-run precision for nicotine was $6.16-12.45 \%$ across the linear range and for cotinine was $7.15-13.60 \%$. Inter-run accuracy for nicotine was -11.14 to $4.46 \%$ and for cotinine was -13.80 to $4.04 \%$ across the same linear range. Intrarun precision for nicotine was $5.42 \%$ and for cotinine was $4.30 \%$. Because nicotine is ubiquitous, "stripped" plasma was used to prepare standards. Plasma was stripped using gravity feed through an activated charcoal column. Quality control samples were not prepared from stripped plasma. Quality control samples 5/3, 25/100, and 60/500 (nicotine/cotinine) were interspersed among the subject samples. Using stripped plasma, blanks were $<20 \%$ of the response for the limit of quantitation, $2.0 \mathrm{ng} / \mathrm{ml}$ for nicotine and $1.0 \mathrm{ng} / \mathrm{ml}$ for cotinine, respectively.

Statistical analyses. For the first behavioral experiment, initial analyses revealed that there were no differences between mice that received sham surgeries and injections and mice that did not receive sham surgeries and injections. Therefore, the data were collapsed within each treatment group, and three (duration: acute, chronic, withdrawal) $\times$ two (treatment: nicotine, saline) ANOVAs were conducted to examine differences in contextual, cued, baseline, immediate, and preCS freezing. Tukey's test-adjusted contrasts were performed to examine differences among groups at a pairwise level. Data from the second behavioral study and plasma nicotine and cotinine data were analyzed using one-way ANOVAs. Follow-up comparisons were conducted using Tukey's honestly significant difference (HSD) analyses. Because nicotine assay values $<2.00 \mathrm{ng} / \mathrm{ml}$ and cotinine assay values $<1.00 \mathrm{ng} / \mathrm{ml}$ were below the level of quantitation (BLQ), all BLQ data points were assigned assay values of $1.99 \mathrm{ng} / \mathrm{ml}$ and 0.99 $\mathrm{ng} / \mathrm{ml}$ for analysis of nicotine and cotinine levels, respectively. Analyses were performed using SPSS version 11.0 (SPSS, Chicago, IL).

\section{Results}

The effect of acute, chronic, and withdrawal from chronic nicotine administration on fear conditioning

The results of the first behavioral experiment are presented in Figure 1 . A $3 \times 2$ ANOVA revealed a significant treatment duration by drug interaction for contextual fear conditioning $\left(F_{(2,82)}=\right.$ $16.30 ; p<0.05)$. Follow-up Tukey's test-adjusted comparisons revealed that acute nicotine administration $(0.09 \mathrm{mg} / \mathrm{kg})$ significantly enhanced contextual fear conditioning compared with all other treatment groups ( $p<0.05$ for all comparisons), and there was no effect of chronic nicotine treatment on contextual fear conditioning ( $p>0.05$ compared with mice treated acutely with saline, mice treated chronically with saline, and mice withdrawn from chronic saline treatment). Mice withdrawn from chronic nicotine demonstrated significantly lower levels of contextual fear conditioning than all other treatment groups $(p<0.05$ for all comparisons). There were no differences among groups in cued fear conditioning $(p>0.05)$. Nor were there differences among groups in baseline, immediate, and preCS freezing (data not shown; $p>0.05$ ), suggesting that the effect of nicotine on contextual freezing was not attributable to baseline differences in locomotor activity, sensitivity to shock, or generalized freezing (as measured by baseline freezing, immediate freezing, and preCS freezing, respectively).

It is possible that impairments demonstrated by mice withdrawn from chronic nicotine were attributable to the effect of administration of nicotine $1 \mathrm{~d}$ before training rather than to chronic administration of nicotine for $12 \mathrm{~d}$ before training. To

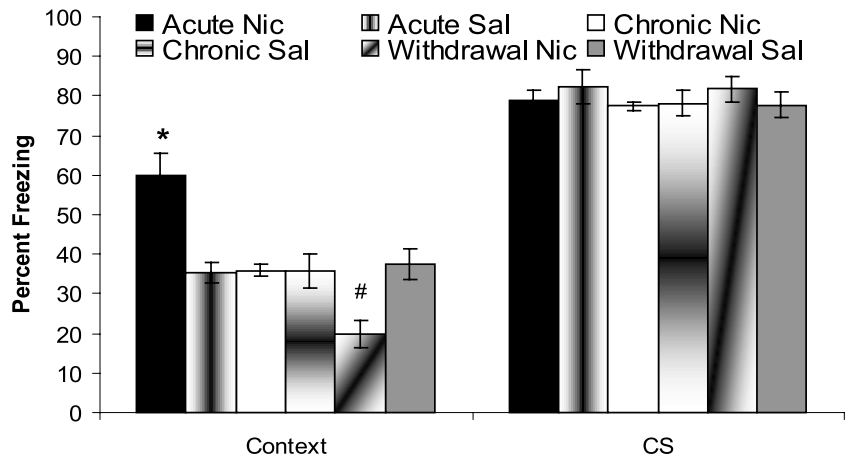

Figure 1. The effects of acute nicotine administration, chronic nicotine administration, and withdrawal from chronic nicotine administration on contextual and cued fear conditioning. Post hoc Tukey's HSD analyses revealed that mice treated acutely with $0.09 \mathrm{mg} / \mathrm{kg}$ nicotine froze significantly more to the context than all other groups of animals. Mice withdrawn for $24 \mathrm{~h}$ from $12 \mathrm{~d}$ of chronic nicotine treatment $(6.3 \mathrm{mg} / \mathrm{kg} / \mathrm{d})$ before training demonstrated significantly lower levels of contextual freezing than all other groups. There was no effect of acute nicotine, chronic nicotine, or withdrawal from chronic nicotine administration on cued fear conditioning. ${ }^{*} p<0.05$ and ${ }^{\#} p<0.05$ compared with all other groups.

examine this possibility, two groups of mice were trained $1 \mathrm{~d}$ after an injection of either nicotine $(0.09 \mathrm{mg} / \mathrm{kg}$, i.p. $)$ or saline. There were no significant differences between the groups in freezing to the context and freezing to the CS (data not shown; $p>0.05$ ). In addition, there were no differences between groups in baseline, immediate, and preCS freezing $(p>0.05)$. These data suggest that impairments in contextual fear conditioning demonstrated by mice withdrawn from chronic nicotine occurred as a result of withdrawal from chronic administration of nicotine.

\section{Plasma nicotine and cotinine}

The results of plasma nicotine and cotinine analysis are in Table 1. Main effects of nicotine treatment (i.e., acute vs chronic vs withdrawal) on plasma levels of nicotine $\left(F_{(3,28)}=23.97 ; p<\right.$ $0.05)$ and cotinine $\left(F_{(3,28)}=77.87 ; p<0.05\right)$ were found. Tukey's test-adjusted contrasts revealed that plasma nicotine levels in mice treated acutely and mice treated chronically with nicotine were similar $(p>0.05)$. Mice treated with saline and mice withdrawn from chronic nicotine had nicotine assay values that were BLQ. Mice treated chronically with nicotine had plasma cotinine values that were significantly higher than all other groups $(p<$ 0.05 for all comparisons). Consistent with data indicating that cotinine has a longer half-life than nicotine (Petersen et al., 1984; Ghosheh et al., 1999), plasma levels of cotinine were 10 times higher in mice treated chronically with nicotine than in mice treated acutely with nicotine. In addition, plasma nicotine and plasma cotinine were BLQ in mice that had their micro-osmotic pumps removed $1 \mathrm{~d}$ before plasma sample collection.

\section{Effects of acute nicotine administration on nicotine} withdrawal-induced deficits in contextual fear conditioning Thus far, the data indicate that withdrawal from nicotine (6.3 $\mathrm{mg} / \mathrm{kg} / \mathrm{d}$ for $12 \mathrm{~d}$ ) $24 \mathrm{~h}$ before training is associated with deficits in contextual fear conditioning. Research indicates that nicotine withdrawal-associated deficits in cognition can be reversed by acute nicotine administration in both animal models and in humans (Bell et al., 1999; Semenova et al., 2003). Thus, we examined whether a challenge dose of nicotine $(0.09 \mathrm{mg} / \mathrm{kg})$ administered 5 min before training and testing could reverse the withdrawalassociated deficits. Figure 2 depicts the results of this behavioral experiment. 
Table 1. Comparison of plasma nicotine levels and plasma cotinine levels across conditions

\begin{tabular}{llcc}
\hline Treatment & Average $(\mathrm{ng} / \mathrm{ml})$ & SD $(\mathrm{ng} / \mathrm{ml})$ & Range $(\mathrm{ng} / \mathrm{ml})$ \\
\hline Plasma nicotine & & & \\
$\quad$ Saline & BLQ & & $<2.00$ \\
Acute nicotine & $13.40^{a, b}$ & 3.73 & $7.30-18.50$ \\
$\quad$ Chronic nicotine & $13.00^{a, b}$ & 5.85 & $5.70-23.60$ \\
$\quad$ Nicotine withdrawn & BLQ & & $<2.00$ \\
Plasma cotinine & BLQ & & $<1.00$ \\
Saline & 3.90 & 2.29 & $1.10-7.60$ \\
Acute nicotine & $39.80^{a, b, c}$ & 10.98 & $21.90-55.10$ \\
Chronic nicotine & $\mathrm{BLQ}^{d}$ & & $<1.00-1.90$ \\
Nicotine withdrawn & &
\end{tabular}

${ }^{a_{p}}<0.05$ compared with saline-treated mice.

${ }^{b} p<0.05$ compared with mice withdrawn from chronic nicotine treatment.

${ }^{c} p<0.05$ compared with mice treated with acute nicotine.

${ }^{d}$ Two mice that were withdrawn from chronic nicotine administration had plasma cotinine levels that were $>1.00 \mathrm{ng} / \mathrm{ml}$ (values, $1.30 \mathrm{and} 1.90 \mathrm{ng} / \mathrm{ml}$ ).

\section{Discussion}

The present study is the first to demonstrate the development of both tolerance and withdrawal symptoms associated with the effects of a physiologically relevant dose of nicotine on hippocampusdependent learning. Previous studies have shown that acute nicotine dose dependently enhances hippocampus-dependent contextual fear conditioning (Gould and Wehner, 1999; Gould and Higgins, 2003; Wehner et al., 2004; Davis and Gould, 2005). As depicted in Figure 1, an acute dose of nicotine and a chronic dose of nicotine that produced the same plasma nicotine levels did not produce the same behavioral effects; acute nicotine treatment

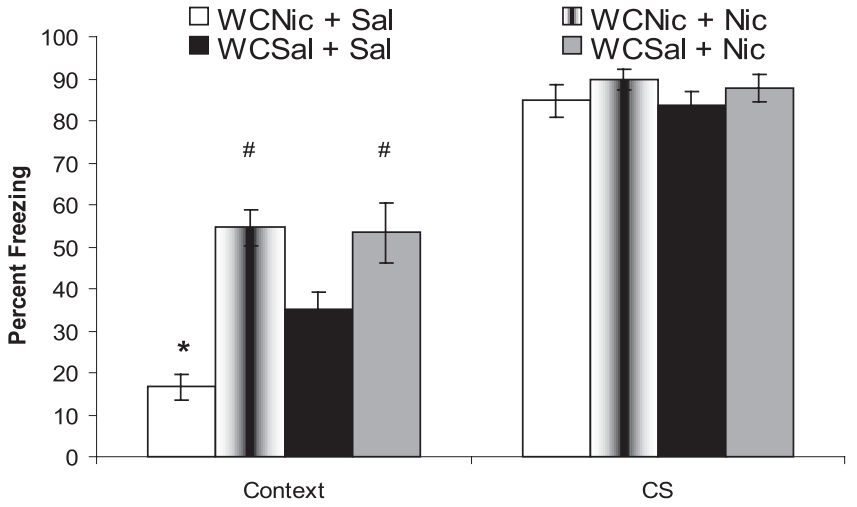

Figure 2. The effect of an acute dose of nicotine or saline on contextual and cued fear conditioning in mice withdrawn from chronic nicotine treatment or withdrawn from chronic saline treatment. Tukey's HSD analyses revealed that mice withdrawn from chronic nicotine that received saline at training and testing (WCNic + Sal) froze significantly less to the context than mice withdrawn from chronic nicotine that received a dose of nicotine at training and testing (WCNic + Nic), mice withdrawn from chronic saline treatment that received a dose of saline at training and testing (WCSal + Sal), and mice withdrawn from chronic saline treatment that received a dose of nicotine at training and testing (WCSal + Nic). In addition, mice withdrawn from chronic saline that received an acute dose of nicotine froze significantly more to the context than mice withdrawn from chronic saline that received an acute dose of saline at training and testing. There was no effect on cued fear conditioning. ${ }^{*} p<0.05$ compared with all other groups; ${ }^{\#} p<0.05$ compared with mice withdrawn from chronic saline that received saline at training and testing (WCSal + Sal).

A significant treatment by drug interaction existed for contextual fear conditioning $\left(F_{(3,40)}=4.43 ; p<0.05\right)$. As with acute treatment, mice treated chronically with saline that received acute nicotine $(0.09 \mathrm{mg} / \mathrm{kg})$ at training and testing demonstrated higher levels of contextual fear than mice treated chronically with saline that received saline at training and testing $(p<0.05)$. Also, mice withdrawn for $24 \mathrm{~h}$ from nicotine after $12 \mathrm{~d}$ of chronic treatment demonstrated deficits in contextual fear conditioning compared with saline-treated mice $(p<0.05)$, replicating the observed withdrawal deficits. Administration of an acute dose $(0.09 \mathrm{mg} / \mathrm{kg})$ of nicotine at both training and testing reversed this deficit. In fact, mice withdrawn from chronic nicotine treatment that received acute nicotine demonstrated levels of contextual fear that were similar to mice treated chronically with saline that received acute nicotine at training and testing $(p>0.05)$. No differences between groups in baseline, immediate, preCS, or CS freezing $(p>0.05)$ were found. enhanced and chronic nicotine treatment failed to enhance contextual fear conditioning. Furthermore, mice withdrawn from chronic nicotine treatment demonstrated deficits in contextual fear conditioning compared with their saline-treated counterparts. The mice withdrawn from nicotine had plasma nicotine levels below quantitation (Table 1). Notably, plasma nicotine levels in mice treated acutely and chronically with nicotine were within the low end of the range of plasma nicotine levels (10-50 $\mathrm{ng} / \mathrm{ml}$ ) demonstrated by smokers (Benowitz et al., 1989; Henningfield and Keenan, 1993).

It is possible that relapse occurs after withdrawal from nicotine as an attempt to ameliorate learning-related deficits. In support, an acute challenge dose of nicotine not only reversed the deficit seen in mice withdrawn from chronic nicotine, but also induced levels of contextual fear conditioning that were similar to levels found in control mice treated with an acute dose of nicotine before training and testing. Furthermore, acute nicotine produced a greater percentage increase in contextual fear conditioning in mice withdrawn from chronic nicotine than in mice withdrawn from chronic saline (i.e., a change from $16.7 \%$ contextual freezing in nicotine withdrawn mice to $55.6 \%$ freezing in nicotine withdrawn mice administered acute nicotine vs a change from $35.2 \%$ freezing in saline withdrawn mice to $53.3 \%$ freezing in saline withdrawn mice administered acute nicotine) (Fig. 2). Because the percentage of contextual freezing in mice withdrawn from chronic nicotine treatment that received acute nicotine is similar to the percentage of contextual freezing in mice withdrawn from chronic saline treatment that received acute nicotine, it is unclear whether the greater percentage increase in contextual conditioning in mice withdrawn from nicotine reflects sensitization to the effects of nicotine or a reversal of the withdrawal associated deficit. Thus, it will be important to investigate whether mice withdrawn from chronic nicotine are sensitized to the acute effect of nicotine on contextual fear conditioning.

The neural mechanisms altered during nicotine withdrawal are unknown. However, receptor-level changes in nAChR function and number could contribute to the disruptive effects of nicotine withdrawal on contextual fear conditioning. A number of studies have found that chronic nicotine exposure is accompanied by an increase in nAChR binding sites (Marks et al., 1983, 2004; Fenster et al., 1997; Peng et al., 1997) and by nAChR desensitization (Schwartz and Kellar, 1985; Marks et al., 1993; Fenster et al., 1997; Olale et al., 1997; Wooltorton et al., 2003). Researchers propose that increases in $\mathrm{nAChR}$ binding sites may be a compensatory mechanism induced by $\mathrm{nAChR}$ desensitization (Marks 
et al., 1983; Schwartz and Kellar, 1985). Furthermore, evidence from pharmacokinetic studies of nicotine (for review, see Benowitz et al., 1989; Henningfield and Keenan, 1993; Mathieu-Kia et al., 2002) suggests that periods of abstinence (i.e., when an individual attempts to quit smoking) could cause some desensitized nAChRs to recover function. Consistent with this suggestion, Gentry et al. (2003) demonstrated that desensitized nAChRs can recover function in the absence of nicotine in vitro. These receptor-level changes could account for the behavioral tolerance demonstrated by mice treated chronically with nicotine and for deficits in contextual fear conditioning demonstrated by mice withdrawn from chronic nicotine in the present study.

Numerous nAChR subtypes exist (for review, see Picciotto et al., 2000), and alterations in the function and number of any receptor subtype could account for behavioral changes. Results from our laboratory (Davis and Gould, 2005) and from Wehner et al. (2004) indicate that $\alpha 4 \beta 2 \mathrm{nAChRs}$ are involved in the acute effects of nicotine on contextual fear conditioning. Furthermore, Marks et al. (2004) reported that chronic nicotine, at a dose that produces comparable plasma nicotine levels to those seen in the present study, results in half-maximal upregulation of $\alpha 4 \beta 2$ nAChRs. Combined, these studies suggest that alterations in $\alpha 4 \beta 2$ nAChR function and/or number that occur with chronic exposure to nicotine could contribute to the changes in contextual fear conditioning observed in the present studies; this will be an important topic for additional study.

Just as nAChR subtype involvement varies across behaviors, nicotine may have divergent effects on different behaviors and underlying neural areas. Data from the present experiments, indicating that acute, chronic, and withdrawal from chronic nicotine administration did not alter hippocampus-independent cued fear conditioning, suggest that the effects of nicotine do not generalize across learning paradigms. In addition, these data suggest that nicotine does not increase fear in general, but rather nicotine enhances learning of a hippocampus-dependent association [i.e., contextual fear conditioning (Phillips and LeDoux, 1992; Logue et al., 1997)]. It is possible that the null effect of acute nicotine on cued fear conditioning was a result of ceiling-level performance. However, previous research (Gould et al., 2004) has used fear-conditioning protocols that produce lower levels of conditioning to demonstrate that the lack of effect of acute nicotine on hippocampus-independent cued fear conditioning is not caused by a ceiling effect. Thus, acute nicotine differentially affects cued and contextual fear conditioning.

Additionally, it is possible that the effects of chronic nicotine may vary across hippocampus-dependent tasks. Levin et al. (1990, 1999) demonstrated that chronic nicotine administration after acquisition of the radial-arm maze enhanced future hippocampus-dependent spatial working memory performance in that task. Contextual and spatial learning involve different neural and cellular substrates (El Ghundi et al., 1999; Graves et al., 2002; Burwell et al., 2004). Thus, differences in the effects of chronic nicotine on these neural and cellular substrates could account for the different effects of chronic nicotine on these behaviors. However, methodological differences such as examining the effects of chronic nicotine on acquisition of a task versus examining the effects of chronic nicotine on performance of a previously learned task make a direct comparison between our results and the results of Levin et al. $(1990,1999)$ difficult. We have begun to examine the effects of nicotine on acquisition of a version of fear conditioning that involves working memory to address these issues (Gould et al., 2004).

In summary, the effects of nicotine on cognition could sup- port the development and maintenance of nicotine addiction through multiple mechanisms. First, the initial use of nicotine could facilitate cognitive processes, which could lead to repeated use and the development of drug-context associations that could precipitate cravings. Second, the development of tolerance for the cognitive-enhancing effects of nicotine could lead to increased use. Finally, withdrawal from nicotine could produce deficits in cognitive function that could contribute to relapse. The results of the present study suggest that one or more of these mechanisms could contribute to nicotine addiction.

\section{References}

Bell SL, Taylor RC, Singleton EG, Henningfield JE, Heishman SJ (1999) Smoking after nicotine deprivation enhances cognitive performance and decreases tobacco craving in drug abusers. Nicotine Tob Res 1:45-52.

Benowitz NL, Porchet H, Jacob P (1989) Nicotine dependence and tolerance in man: pharmacokinetic and pharmacodynamic investigations. Prog Brain Res 79:279-287.

Burwell RD, Saddoris MP, Bucci DJ, Wiig KA (2004) Corticohippocampal contributions to spatial and contextual learning. J Neurosci 24:3826-3836

Caggiula AR, Donny EC, White AR, Chaudhri N, Booth S, Gharib MA, Hoffman A, Perkins KA, Sved AF (2001) Cue dependency of nicotine selfadministration and smoking. Pharmacol Biochem Behav 70:515-530.

Center for Disease Control (2004) Cigarette smoking among adults-United States, 2002. MMWR 53:428-431. Available at http://www.cdc.gov/ tobacco/research_data/adults_prev/MM52804.pdf.

Chiamulera C (2005) Cue reactivity in nicotine and tobacco dependence: a "multiple-action" model of nicotine as a primary reinforcement and as an enhancer of the effects of smoking-associated stimuli. Brain Res Brain Res Rev 48:74-97.

Davis JA, Gould TJ (2005) The effects of DHBE and MLA on nicotineinduced enhancement of contextual fear conditioning. Psychopharmacology, in press.

El Ghundi M, Fletcher PJ, Drago J, Sibley DR, O’Dowd BF, George SR (1999) Spatial learning deficit in dopamine $\mathrm{D}(1)$ receptor knockout mice. Eur J Pharmacol 383:95-106.

Fagen ZM, Mansvelder HD, Keath JR, McGehee DS (2003) Short- and longterm modulation of synaptic inputs to brain reward areas by nicotine. Ann NY Acad Sci 1003:185-195.

Fenster CP, Rains MF, Noerager B, Quick MW, Lester RA (1997) Influence of subunit composition on desensitization of neuronal acetylcholine receptors at low concentrations of nicotine. J Neurosci 17:5747-5759.

Gentry CL, Wilkins LH, Lukas RJ (2003) Effects of prolonged nicotinic ligand exposure on function of heterologously expressed, human $\alpha 4 \beta 2$ and $\alpha 4 \beta 4$-nicotinic acetylcholine receptors. J Pharmacol Exp Ther 304:206-216

Ghosheh O, Dwoskin LP, Li W, Crooks PA (1999) Residence times and half-lives of nicotine metabolites in rat brain after acute peripheral administration of $\left[2^{\prime}-{ }^{14} \mathrm{C}\right]$ nicotine. Drug Metab Dispos 27:1448-1455.

Gould TJ, Higgins JS (2003) Nicotine enhances contextual fear conditioning in C57BL/6 J mice at 1 and 7 days post-training. Neurobiol Learn Mem 80:147-157.

Gould TJ, Wehner JM (1999) Nicotine enhancement of contextual fear conditioning. Behav Brain Res 102:31-39.

Gould TJ, Feiro O, Moore D (2004) Nicotine enhances trace cued fear conditioning but not delay cued fear conditioning in C57BL/6 mice. Behav Brain Res 155:167-173.

Graves L, Dalvi A, Lucki I, Blendy JA, Abel T (2002) Behavioral analysis of CREB alphadelta mutation on a B6/129 F1 hybrid background. Hippocampus 12:18-26.

Henningfield JE, Keenan RM (1993) Nicotine delivery kinetics and abuse liability. J Consult Clin Psychol 61:743-750.

Hyman SE, Malenka RC (2001) Addiction and the brain: the neurobiology of compulsion and its persistence. Nat Rev Neurosci 2:695-703.

Kenny PJ, Markou A (2001) Neurobiology of the nicotine withdrawal syndrome. Pharmacol Biochem Behav 70:531-549.

Kleinman KM, Vaughn RL, Christ S (1973) Effects of cigarette smoking and smoking deprivation on paired-associate learning of high and low meaningful nonsense syllables. Psychol Reports 32:963-966.

Lazev AB, Herzog TA, Brandon TH (1999) Classical conditioning of envi- 
ronmental cues to cigarette smoking. Exp Clin Psychopharmacol $7: 56-63$.

Levin ED (2002) Nicotinic receptor subtypes and cognitive function. J Neurobiol 53:633-639.

Levin ED, Lee C, Rose JE, Reyes A, Ellison G, Jarvik M, Gritz E (1990) Chronic nicotine and withdrawal effects on radial-arm maze performance in rats. Behav Neural Biol 53:269-276.

Levin ED, Christopher NC, Weaver T, Moore J, Brucato F (1999) Ventral hippocampal ibotenic acid lesions block chronic nicotine-induced spatial working memory improvements in rats. Brain Res Cogn Brain Res 7:405-410.

Logue SF, Paylor R, Wehner JM (1997) Hippocampal lesions cause learning deficits in inbred mice in the Morris water maze and conditioned-fear task. Behav Neurosci 111:104-113.

Marks MJ, Burch JB, Collins AC (1983) Effects of chronic nicotine infusion on tolerance development and nicotinic receptors. J Pharmacol Exp Ther 226:817-825

Marks MJ, Grady SR, Collins AC (1993) Downregulation of nicotinic receptor function after chronic nicotine infusion. J Pharmacol Exp Ther 266:1268-1276.

Marks MJ, Rowell PP, Cao J, Grady SR, McCallum SE, Collins AC (2004) Subsets of acetylcholine-stimulated ${ }^{86} \mathrm{Rb}^{+}$efflux and $\left[{ }^{125} \mathrm{I}\right]$-epibatidine binding sites in C57BL/6 mouse brain are differentially affected by chronic nicotine treatment. Neuropharmacology 46:1141-1157.

Mathieu-Kia AM, Kellogg SH, Butelman ER, Kreek MJ (2002) Nicotine addiction: insights from animal studies. Psychopharmacology 162:102-118.

Naidong W, Shou W, Chen YL, Jiang X (2001) Novel liquid chromatographic-tandem mass spectrometric methods using silica columns and aqueous-organic mobile phases for quantitative analysis of polar ionic analytes in biological fluids. J Chromatogr B Biomed Sci Appl 754:387-399.

Nestler EJ (2002) Common molecular and cellular substrates of addiction and memory. Neurobiol Learn Mem 78:637-647.

Olale F, Gerzanich V, Kurytatov A, Wang F, Lindstrom J (1997) Chronic nicotine exposure differentially affects the function of human $\alpha 3, \alpha 4$, and $\alpha 7$ neuronal nicotinic receptor subtypes. J Pharmacol Exp Ther 283:675-683.

Peng X, Gerzanich V, Anand R, Wang F, Lindstron J (1997) Chronic nicotine treatment up-regulates $\alpha 3$ and $\alpha 7$ acetylcholine receptor subtypes expressed by the human neuroblastoma cell line SH-SY5Y. Mol Pharmacol 51:776-784.

Petersen DR, Norris KJ, Thompson JA (1984) A comparative study of the disposition of nicotine and its metabolites in three inbred strains of mice. Drug Metab Dispos 12:725-731.

Phillips RG, LeDoux JE (1992) Differential contribution of amygdala and hippocampus to cued and contextual fear conditioning. Behav Neurosci 106:274-285

Picciotto MR, Caldarone BJ, King SL, Zachariou V (2000) Nicotinic receptors in the brain. Links between molecular biology and behavior. Neuropsychopharmacology 22:451-465.

Schwartz RD, Kellar KJ (1985) In vivo regulation of $\left[{ }^{3} \mathrm{H}\right]$ acetylcholine recognition sites in brain by nicotinic cholinergic drugs. J Neurochem 45:427-433.

Semenova S, Bespalov A, Markou A (2003) Decreased prepulse inhibition during nicotine withdrawal in DBA/2J mice is reversed by nicotine selfadministration. Eur J Pharmacol 472:99-110.

Snyder FR, Davis FC, Henningfield JE (1989) The tobacco withdrawal syndrome: performance decrements assessed on a computerized test battery. Drug Alcohol Depend 23:259-266.

Tinsley MR, Quinn JJ, Fanselow MS (2004) The role of muscarinic and nicotinic cholinergic neurotransmission in aversive conditioning: comparing pavlovian fear conditioning and inhibitory avoidance. Learn Mem 11:35-42.

Wehner JM, Keller JJ, Keller AB, Picciotto MR, Paylor R, Booker TK, Beaudet A, Heinemann SF, Balogh SA (2004) Role of neuronal nicotinic receptors in the effects of nicotine and ethanol on contextual fear conditioning. Neuroscience 129:11-24.

Wooltorton JR, Pidoplichko VI, Broide RS, Dani JA (2003) Differential desensitization and distribution of nicotinic acetylcholine receptor subtypes in midbrain dopamine areas. J Neurosci 23:3176-3185. 